\title{
Cuidadoras de pacientes alcoolistas no município de Santos, SP, Brasil
}

\author{
Caregivers of alcohol addicted patients in the city of Santos, SP, Brazil \\ Cuidadoras de pacientes alcoholicos en el municipio de Santos, SP, Brasil
}

\section{Elizama Cabral Vasconcelos dos Santos', Denise Martin'}

'Universidade Católica de Santos. Santos, SP

Submissão: $08 / 04 / 2008$

Aprovação: 02/03/2009

\section{RESUMO}

O objetivo deste estudo Qualitativo é analisar o significado do alcoolismo para cuidadoras de pacientes dependentes de álcool. Foram realizadas observação etnográfica e entrevistas em profundidade com dez cuidadoras de pacientes alcoolistas em tratamento nos serviços de saúde mental de Santos. O estudo mostrou Que as relações familiares eram instáveis e conflituosas. Houve dificuldade da família em reconhecer a dependência. $\mathrm{O}$ alcoolismo foi aceito como doença Quando o paciente foi internado. O uso abusivo do álcool foi obscurecido pela valorização social do consumo e pelas relações de gênero desiguais. Houve um retraimento da sociabilidade das cuidadoras. As mulheres assumiram o cuidado e atuavam como organizadoras de um cotidiano instável e sofrido.

Descritores: Cuidadores; Alcoolismo; Pesquisa Qualitativa; Família.

\begin{abstract}
The objective of this Qualitative study is to assess the meaning of alcoholism to alcoholic's patient's caregivers. Fieldwork involved comprehensive ethnographic observation and in depth interviews with ten female caregivers of alcoholic patients undergoing treatment in health mental care in Santos. The study showed that family relationships were unstable and conflicting. It was difficult to recognize addiction. Women accepted addiction as illness when the patient was hospitalized. Addiction to alcohol had been hidden by social value of intake and by unequal gender relationships. There has been a social restraint of the caregivers. Women have assumed the care and were organizers of an unstable and painful everyday life.
\end{abstract}

Descriptores: Caregivers; Alcoholism; Qualitative research; Family.

\section{RESUMEN}

El objetivo de este estudio cualitativo es analisar el significado del alcoholismo para las encargadas de pacientes dependientes del alcohol. Se realizaron observaciones etnográfica y entrevistas en detalles con diez encargadas de pacientes alcoholicos en tratamiento en los servicios de salud mental del Municipio de Santos. El estudio ha mostrado Que las relaciones familiares eran inestables y conflictivas. Hubo dificultad por parte de la familia en reconocer la dependencia. El alcoholismo fue aceptado como enfermedad después Que el paciente fue internado. El abuso del alcohol fue encubierto por la valorización social del consumo y por las relaciones de género desiguales. Hubo un recapacitación de la sociabilidad de las encargadas. Las mujeres asumieron el cuidado y actuaban como organizadoras de un día a día inestable y sufrido.

Descriptores: Cuidadores; Alcoholismo; Investigación cualitativa; Família. 


\section{INTRODUÇÃO}

A dependência do álcool é um importante problema de saúde pública. Compromete o cotidiano familiar, envolvendo outras pessoas além do próprio alcoolista. A dependência afeta a economia, as relações no trabalho e a sociabilidade em geral. Os malefícios causados pelo uso abusivo do álcool não podem ser compreendidos restritamente aos danos biológicos. É necessário considerar o contexto cultural envolvido no consumo do álcool.

O álcool é uma substância presente no cotidiano de praticamente todas as pessoas. O uso é naturalizado na nossa sociedade, principalmente relacionado com festas e comemorações, estando ligado a Questões valorizadas socialmente como prazer, liberdade e lazer. Beber é socialmente aprovado entre vários grupos sociais o Que dificulta o estabelecimento de limites entre o consumo recreativo e a dependência.

O diagnóstico do alcoolismo é em geral impreciso, freqüentemente subestimado e feito, via de regra, Quando o paciente já está num estágio avançado da dependência, com claras repercussões físicas, psíquicas e sociais ${ }^{(1)}$.

O Levantamento Domiciliar sobre o uso de Drogas Psicotrópicas no Brasil envolveu as 107 maiores cidades do Brasil (com mais de 200 mil habitantes) e revelou que $68 \%$ das pessoas fazem uso de álcool na vida e Que 11 ,2\% da população é dependente de bebidas alcoólicas ${ }^{(2)}$.

Estudo sobre morbidade psiquiátrica em três centros urbanos brasileiros (São Paulo, Brasília e Porto Alegre) concluiu Que a prevalência combinada de abuso e dependência de álcool ao longo da vida seria de aproximadamente $8 \%$ no conjunto das amostras estudadas, afetando homens em particular ${ }^{(3)}$.

Do ponto de vista epidemiológico, análises comparativas de estudos empíricos de doenças mentais revelam uma constância entre diversas sociedades e contextos sociais: transtornos ligados a substâncias são mais prevalentes entre os homens ${ }^{(4)}$. Desta forma, os homens representam um importante grupo para a compreensão deste transtorno mental.

O uso abusivo do álcool está relacionado a internações psieuiátricas ${ }^{(5)}$, absenteísmo no trabalho, aposentadorias precoces e acidentes no trabalho ${ }^{(6)}$.

A violência doméstica é uma experiência freqüente no cotidiano das famílias com histórico de alcoolismo. Pesquisa realizada em 27 municípios com mais de 200 mil habitantes no estado de São Paulo mostra Que em 52\% dos casos de violência ocorridos dentro de casa o agressor estava alcoolizado ${ }^{(7)}$.

Minayo $^{(8)}$ ressalta Que, embora todas as evidências empíricas revelem Que é o álcool a substância mais significativa na articulação com várias formas de violência, seu status de legalidade torna-o socialmente aceito e largamente consumido.

As evidências dos problemas ocasionados pelo alcoolismo acima citadas mostram o impacto provocado pelo paciente na família e também Quando está hospitalizado. É necessário analisar o significado do alcoolismo no cotidiano daqueles que se responsabilizam pelos pacientes alcoolistas, Que neste estudo se revelaram como cuidadores.

\section{Revisão Teórica}

No Brasil, o cuidar é um papel atribuído social e culturalmente à mulher ${ }^{(9)}$. A bibliografia sobre cuidadores e familiares revela uma extensa produção sobre o tema, referente a idosos dependentes, portadores de doenças crônico-degenerativas - como o Mal de Alzheimer e Acidente Vascular Cerebral (AVC) - pacientes idosos, portadores de distúrbios cognitivos, pacientes portadores do vírus HIV e pacientes com transtornos mentais ${ }^{(10-13)}$. Todavia, não foram encontrados estudos sobre cuidadores de pacientes alcoolistas.

Do ponto de vista dos cuidadores em geral, diversos autores se ocuparam em mostrar como se dá o cuidado no cotidiano, fatores de risco, desgaste do cuidador e estresse $\mathrm{e}^{(9,14,15)}$. É importante compreender como se dá este cuidado no contexto do alcoolismo.

No caso do alcoolista, o cuidado é diferente, pois o paciente não possui grau de dependência similar a outras patologias, tais como AIDS, demências etc. Ao contrário do Que ocorre com outros pacientes, o doente de alcoolismo pode não ser "descoberto". Muitos nunca chegam a ser considerados por si mesmos e nem pelos outros como doentes, embora causem durante a vida muitos problemas.

Para compreender como a família enfrenta o alcoolismo, mais especificamente o cuidador, é necessário olhar para o contexto cultural em Que ela se insere.

Heath ${ }^{(16)}$ mostra Que o álcool tende a ser relacionado de alguma forma com praticamente todos os aspectos da cultura, e são incrivelmente diversos os papéis Que ele assume. Por exemplo, da abstinência ao consumo excessivo crônico e consumo habitual, da admiração por seu poder místico até a depreciação por ser imoral ou tabu. Segundo o autor, as emoções variam muito na pessoa Que bebe, dependendo do Que, Quanto, Quando, em companhia de Quem e assim por diante. Desta forma, a Questão do uso ou abuso de QualQuer substância não pode estar separada dos processos históricos, culturais e do contexto social.

De maneira semelhante, Neves ${ }^{(17)}$ cita Que cada sociedade tem colocado em relevo os padrões institucionalizados de uso das bebidas alcoólicas, a variedade de modos de produção, de motivos e de oportunidades construídas para o ato social de alcoolização. O catálogo dos motivos Que referenciam as maneiras de beber não corresponde, necessariamente, ao resultado do comportamento, mas do aprendizado das atitudes culturalmente atribuídas aos diversos usos.

O consumo de bebidas alcoólicas deve ser relativizado na perspectiva cultural. No Brasil, o consumo do álcool é tolerado socialmente, principalmente por ser uma droga lícita. Existe um tênue limite sobre Quando considerar o alcoolismo como transtorno mental (portanto uma doença) ou um problema relativo ao indivíduo (de caráter moral).

Além das complicações advindas no plano somático e psíquico do paciente, o alcoolismo acarreta profundas repercussões no cotidiano da família. Os cuidadores destes pacientes, embora não sejam objeto da intervenção médica, são obrigados a mudar suas atividades cotidianas para acompanhar o familiar alcoolista em casa e também Quando são internados.

O objetivo deste estudo é analisar o significado do alcoolismo para cuidadores de pacientes dependentes de álcool.

\section{METODOLOGIA}

A pesquisa de campo foi desenvolvida no período de janeiro a 
julho de 2005, no município de Santos, nos serviços de saúde mental, locais, utilizando as técnicas de observação etnográfica densa e entrevistas em profundidade ${ }^{(18,19)}$.

Santos é um município portuário situado a $70 \mathrm{Km}$ da capital do Estado, São Paulo. Em 2004, a população era de 424.665 habitantes. A taxa de urbanização é de 99,4\%. O abastecimento de água, esgoto e coleta de lixo abrange praticamente toda a cidade $^{(20)}$.

Segundo Andreoli et al $^{(21)}$, a reforma da atenção psiQuiátrica na cidade de Santos tem sido considerada como um exemplo para a elaboração de estratégias e modelos de políticas em saúde mental no Brasil. Quando da sua implantação, em maio de 1989, teve repercussão internacional, principalmente por colocar em prática a política de desospitalização do paciente psiQuiátrico de modo agudo, por meio da desativação do hospital psieuiátrico da cidade. Desativado o hospital, a organização dos serviços foi sendo estruturada ao longo dos anos em Centros Comunitários de Atenção Psicossocial (CAPS). O único hospital Que possibilita internação é o Hospital Estadual Guilherme Álvaro, dispondo de uma enfermaria psieuiátrica.

\section{Procedimentos de coleta}

A pesquisa foi realizada nos serviços SENAPS (Seção Núcleo de Atendimento Psicossocial) e SENAT (Seção Núcleo de Atenção ao Toxicodependente), da Secretaria de Saúde do Município de Santos. Estas unidades de saúde são voltadas ao atendimento de pessoas portadoras de diferentes tipos de transtornos mentais, com atividades de caráter preventivo, ações de tratamento e projetos de reabilitação psicossocial. A observação etnográfica foi realizada previamente às entrevistas nos com o objetivo de compreender o contexto do tratamento dos alcoolistas.

Foram realizadas dez entrevistas semi-estruturadas com pessoas Que se apresentaram como o familiar responsável pelos cuidados aos pacientes alcoolistas sendo: duas esposas, três ex-esposas e cinco mães. As entrevistas foram gravadas e a duração média foi de uma hora. As entrevistas foram realizadas nos serviços acima citados ou no domicílio do paciente, Quando consentido pelo familiar. O roteiro utilizado para a realização das entrevistas compreendia desde informações gerais, como nome, idade, religião, escolaridade, ocupação, profissão, número de filhos e tipo de moradia, até chegar ao cotidiano do paciente e do cuidador: Quando o alcoolismo passou a ser considerado um problema, o contexto da internação, Quem é o responsável ou os responsáveis pelos cuidados, entendimento do transtorno e do tratamento, possíveis causas do transtorno, relação com a família e condições de vida.

Foram adotados os seguintes critérios de inclusão para os cuidadores: o paciente pelo Qual é responsável deveria ter pelo menos uma internação devido ao alcoolismo e estar em tratamento terapêutico nos SENAPS ou SENAT. O critério de o paciente ter sido internado define o alcoolismo como doença e o paciente como um dependente de álcool. Os pacientes possuíam sérios comprometimentos físicos devido ao estágio avançado da dependência.

Todas as participantes assinaram o Termo de Consentimento Livre e Esclarecido e a pesquisa foi aprovada pelo Comitê de Ética da Universidade Católica de Santos. As entrevistas foram realizadas até a saturação dos conteúdos, foram transcritas integralmente e analisadas. Após a leitura exaustiva do material, as categorias principais foram recolhidas e agrupadas.

O componente Qualitativo da pesQuisa antropológica consiste essencialmente em empregar atos, fatos, falas e interpretações para formar um modelo lógico Que fosse explicativo dessa realidade, na maioria das vezes inacessível aos indivíduos ${ }^{(22)}$.

\section{Caracterização das Entrevistadas e dos Pacientes}

A faixa etária das esposas e ex-esposas variou entre 29 a 60 anos. Entre as mães, a faixa etária encontrada foi de 65 a 74 anos. Quanto ao grau de escolaridade, a maioria possuía o primeiro grau completo, havendo casos de analfabetas ao nível superior incompleto. Das dez mulheres pesquisadas, oito não exerciam atividades fora do lar. Uma estava aposentada e uma trabalhava como faxineira.

Com relação aos pacientes, a faixa etária encontrada na pesøuisa condiz com os dados da literatura sobre os alcoolistas em uma fase progressiva da doença ${ }^{(23)}$. A faixa etária variou de 41 a 48 anos entre os filhos. Com relação aos maridos, variou de 41 a 61 anos. Dos dez pacientes, sete estavam desempregados no momento da pesquisa, um estava aposentado por invalidez, um era funcionário público estadual e um estava trabalhando.

Todas as famílias pesquisadas moravam em Santos. As moradias, em geral, eram de alvenaria, com pelo menos dois cômodos, cozinha e banheiro. Algumas famílias eram proprietárias dos imóveis, outros eram alugados, Quase sempre com a família ampliada. Com relação aos locais de moradia, alguns residiam em bairros de camada média baixa e outros em bairros populares.

\section{RESULTADOS E DISCUSSÃO}

\section{Relações Familiares no Contexto do Alcoolismo}

As relações familiares no contexto do alcoolismo são fundamentais para compreender o cotidiano do cuidador e o significado da doença.

Todas as entrevistadas exerciam o papel de cuidadoras dos pacientes desde o início das conseQüências da dependência do álcool. A organização da casa estava centrada no papel do pai como provedor. No começo dos sintomas da dependência, a maioria das entrevistadas foi obrigada a trabalhar fora, em conseQüência das dificuldades econômicas enfrentadas pela família. Tornaram-se responsáveis por parte do orçamento doméstico.

No momento do estudo, os pacientes não possuíam mais condições de prover a família em virtude das conseeüências da dependência. Em alguns casos, era impossível para a mulher trabalhar fora de casa, devido aos cuidados com os filhos. Algumas famílias passaram a depender de outros parentes para sustentá-las.

O cotidiano descrito pelas entrevistadas era instável e permeado de conflitos. Os relacionamentos eram, muitas vezes, caracterizados pela ameaça, desøualificação e ciúme. A agressividade interferia no relacionamento cotidiano.

Observou-se Que a violência doméstica era um fato concreto na vida destas famílias. As falas das entrevistadas deixaram claro Que o ambiente familiar se caracterizava pela desarmonia e desconfiança:

"Ele cismava com o meu filho mais velho... deixava ele fora, o menino tem muita mágoa dele, sabe? Ele deixava ele de castigo fora de casa, ele sofreu muito, além de mim".(A.M., 59 anos, ex-esposa).

"Quando ele bebe, fica agressivo, Quebra tudo, fala sem parar, 
provoca todas as pessoas, não dorme. Os meus filhos reclamam, pois não conseguem dormir, não descansam, e no dia seguinte eles precisam trabalhar (...)". (I., 60 anos, esposa)

Algumas mulheres relataram Que conseguiam, nesse ambiente hostil e ameaçador, enfrentar seu agressor usando os mesmos métodos.

O alcoolismo dos parentes levou a maioria das cuidadoras ao isolamento. Aos poucos, elas deixaram de freqüentar os ambientes sociais com medo de o paciente beber e promover cenas vexatórias.

Os problemas causados pelo uso do álcool afetaram o cotidiano dos familiares não alcoolistas. Para usar o álcool os pacientes vendiam os objetos encontrados em casa. Era necessário manter tudo trancado ou fechado. Segundo as entrevistadas, estes objetos valiam apenas o necessário para a compra imediata da bebida:

"Não deixava ninguém dormir, pedia dinheiro, bagunçava a casa toda procurando dinheiro, ficava devendo, pagava um e ficava devendo para outros. Em relação ao dinheiro precisava constantemente estar escondido para Que ele não usasse para comprar o álcool. Corria para o mercado para gastar antes dele chegar em casa, mas às vezes não dava tempo, eu também estava ficando compulsiva, em relação ao dinheiro, gastar antes dele começar a pedir... eu ficava com medo dele gastar". (V., 29 anos, ex-esposa).

De maneira geral, observou-se que as cuidadoras referiam sempre condutas previsíveis e repetitivas no cotidiano. Além disso, os pacientes remetiam freQüentemente a situações de constrangimento dentro e fora de casa.

As cuidadoras reconheciam a dificuldade em lidar com este tipo de paciente. As rotinas se organizavam a partir do estado de embriaguez e das oscilações constantes de humor. A família não conseguia estabelecer regras de convivência, por mínimas Que fossem. A relação entre pais e filhos era geralmente conflituosa. Campos $^{(24)}$, estudando narrativas dos Alcoólicos Anônimos (AA), mostra como a doença alcoólica extravasa o limite intrapessoal, possibilitando a representação do alcoolismo como uma "doença de família".

O sofrimento cotidiano foi relacionado aos comportamentos Que denunciavam que o paciente começava a ter problemas com o consumo do álcool. Todavia, é necessário compreender a partir de Que momento o uso abusivo do álcool passou a ser reconhecido como doença.

\section{O Reconhecimento do Consumo de Álcool como Doença}

As cuidadoras não reconheciam um limite preciso entre o beber por prazer e o beber dependente. Foi difícil perceber Que o consumo de álcool estava se tornando uma dependência.

As cuidadoras deste estudo provavelmente já vinham sofrendo as conseqüências da dependência do álcool muito antes do seu reconhecimento como doença.

O alcoolismo como doença surgiu nas entrevistas a partir do momento em Que o paciente foi internado. Ou seja, num estágio em Que a dependência estava bastante avançada. A intensidade do consumo e a perda de controle sobre a bebida foram características apontadas pelas entrevistadas.
A partir da internação, o alcoolista passou a ser visível como um doente. Até o uso do álcool se tornar intolerável, a família não associava o consumo aos problemas apresentados pelos pacientes. O alcoolismo foi compreendido como doença somente Quando os malefícios trazidos pelo uso do álcool emergiram e extrapolaram o limite do suportável - Que parece ser um limite bastante amplo, como foi mostrado no item das relações familiares.

É importante compreender em Que momento as mulheres começam a nomear o beber dos seus parentes como doença. Antes do reconhecimento da doença, o comportamento dos pacientes era entendido moralmente ou como característica de personalidade, escapando assim à concepção de doença. Nesta perspectiva, como mostra Neves ${ }^{(17)}$, o beber é associado a um desvio individual e não a um comportamento social. As seguintes falas ilustram a situação:

"Eu não pensava Que era doença, eu pensava que ele estava com a cabeça perturbada, pois em uma hora estava normal, em outra fazia coisas Que eu não acreditava. Passeava, saia com a filha dele, ficava com a menina no colo enquanto eu fazia as coisas, porQue eu era chata: já Que você não está trabalhando, não está fazendo nada... Eu achava Que ele estava perturbado, e Que isso não era doença”. (V., 29 anos, ex-esposa).

"Ninguém gosta dele, principalmente os meus irmãos. Eles dizem Que ele é vagabundo, não Quer trabalhar, mas eu sei Que ele é doente, começou a beber por causa das pressões que os meus irmãos faziam com ele". (I.60 anos, esposa)

Observou-se Que entre a identificação das primeiras manifestações e o reconhecimento de Que esse comportamento poderia indicar uma doença se passaram muitos anos.

As entrevistas deixaram evidente Que a família passa por uma transformação intensa na constatação da dependência do álcool, ou seja, da doença. As cuidadoras demonstraram Que o alcoolismo começou devagar, gradualmente e foi avançando sem Que os familiares percebessem.

A difícil percepção da relação álcool/doença foi encontrada nas falas. O uso do álcool não era considerado como droga.

Segundo as entrevistadas, os bebedores não demonstravam Que estavam fazendo uso abusivo do álcool, procurando passar uma imagem de normalidade no cotidiano. Esta normalidade se relacionava à valorização e naturalização do consumo do álcool em nossa sociedade, como foi mostrado anteriormente. Neves ${ }^{(17)}$ comenta Que o uso do álcool não é necessariamente uma patologia e deve estar situado no Quadro mais amplo de uso de bebidas e outras drogas lícitas e ilícitas.

Para as mulheres entrevistadas, a dependência foi reconhecida como doença Quando os sintomas estavam no limite e a internação surgiu como única saída. A categoria "doença”, para estas mulheres, surgiu num contexto familiar em Que tais comportamentos ficaram inaceitáveis (após um longo processo de desrespeito, agressões e alterações de humor). A dificuldade de Questionar tais comportamentos está diretamente relacionada às relações de gênero desiguais em nossa sociedade. As relações hierárquicas entre homens e mulheres de certa forma "ocultaram" o Questionamento sobre a dependência. O reconhecimento da doença é também dificultado pelas relações de gênero desiguais ${ }^{(25)}$. Assim, a identificação dos 
primeiros sinais da dependência foi obscurecida.

\section{O Cotidiano das Cuidadoras e o Cuidar}

Vários aspectos da sociabilidade do cuidador ficaram comprometidos. Este comprometimento se refere à responsabilidade, às despesas domésticas, à incerteza, ao cansaço físico, aos sentimentos de angústia, à insegurança e principalmente ao desânimo.

As entrevistadas relataram as inúmeras demandas Que envolvem o comportamento do paciente, Que representava um peso no cotidiano. Não se sentiam preparadas para lidar com os problemas advindos do alcoolismo, principalmente com o rompimento abrupto da trajetória familiar ou dos planos para o futuro.

Houve a necessidade da família se adaptar às novas situações referentes ao cuidado do dependente. Alguém deveria cuidar do paciente, levar para fazer consultas, mandar tomar banho, cortar o cabelo, permanecer acordado enQuanto o paciente não chegava ou não dormia etc. As Queixas das cuidadoras se referiam à rotina, ao isolamento social, à menor participação nas atividades sociais e ao impacto emocional. Além disso, relataram Que precisavam também saber administrar a maior freqüência de conflitos familiares, tendo como foco o paciente alcoolista.

As cuidadoras relataram Que não conseguiam abandonar o seu paciente, mesmo recebendo críticas dos outros familiares e conselhos para abandoná-los.

Observou-se entre as entrevistadas Que a vida não tinha mais objetivo. As mulheres tiveram seu cotidiano invadido pelas demandas dos pacientes estando presentes Quase sempre sentimentos como vergonha, tristeza, mágoas, compaixão e piedade:

“Eu não tenho projeto de vida nenhum, filha... Porque os filhos... A gente diz: pôr na rua. Como é que vai pôr uma pessoa dessa na rua? A família dele mesmo falou pra mim(...)"(A.M., 59 anos, ex-esposa).

"Porque eu digo assim, tem horas que eu fico com raiva, revoltada... mas eu digo: o filho é meu, se eu for deixar na rua... Ele estava lá na Aparecida, sendo carrinheiro dois meses... Se a senhora visse, chegou em casa todo fedido, dessa grossura! $E$ eu passei e vi ele, fui na igreja - todo mundo me conhece lá na igreja - e vi ele, lá... Aí, peguei a irmã: vamos lá, para pegar ele. E ele disse: amanhã eu chego em casa. E esse amanhã durou uma semana! Ele foi andando... e não foi direto pra casa.. "(M.H., 7I anos, mãe).

As esposas Que ainda se dedicavam a cuidar, muitas vezes eram criticadas pelos familiares. Muitos destes pacientes possuíam outros membros na família Que não Queriam se envolver com o cuidado. A obrigação do cuidado permaneceu com as mulheres, esposas ou mães, como mostram as seguintes falas:

“Essa família que ele ainda tem, não Quer tomar conta dele...não, imagina! Elas falaram Que eu não devia tomar conta dele! Eles fazem crítica, ainda, porque eu cuido... fazem, eles dizem que se fossem eles, jamais(...)"(My., 6 I anos, ex-esposa).

“Por pena. Os filhos também estão com pena Nós sabemos se abandonar ele vai para a rua, vai para a sarjeta. Sou kardecista. A gente não está aQui à toa, não estamos de passagem, algumas coisas... Eu penso Que ele pode, ser o filho que eu abandonei em outras vidas, vou ter Que pagar com ele aqui... Passei a cuidar... É difícil para todo mundo, não se compara às outras doenças físicas, ter que dar um banho, comidinha na hora certa, mas alcoolista você não segura, Quando volta não está mais, porQue tem duas personalidades, irmãos gêmeos, sempre se espera o pior."(V., 45 anos, esposa).

No cotidiano do cuidado, as mulheres passaram por situações de vulnerabilidade, fragilidade e precariedade diante das situações apresentadas pelo familiar doente.

As falas demonstraram a busca em reconstruir relações cotidianas e a tentativa de fortalecer os frágeis laços familiares. Apesar da sobrecarga, das angústias, cansadas pelo acúmulo de funções, as mulheres sempre traziam o cuidar como uma obrigação, principalmente as mães. Ainda Que reclamassem, referiram Que só elas poderiam cuidar dos filhos, justificando um amor inquestionável pelos pacientes.

“ Ah, cuido porque eu sou mãe. Ah, olha, eu me sinto as duas coisas tanto na obrigação, Quanto no sentimento, porQue eu não posso deixar meu filho desse jeito, eu só penso isso: na minha falta, o Que vai ser dele? Quem vai cuidar dele? Onde ele vai ficar? Vai ficar jogado na rua?" (T., 72 anos, mãe).

"Se eu não cuidar, ele vai para a rua... ele já tinha morrido. Outro dia levou um murro no rosto, chegou em casa com o olho inchado".(M.H., 7 I anos, mãe).

Finalmente, a partir das histórias dessas famílias, pode-se observar a trajetória dos pacientes que contam com o cuidado das mães e/ ou esposas, e refletir como seria na sua ausência. Neste sentido, a família tem uma importância fundamental no cuidado.

\section{CONSIDERAÇÕES FINAIS}

Este trabalho mostra Que os alcoolistas, mesmo Quando desorganizam a rotina estabelecida na família, demoram a ser considerados como pessoas que necessitam de cuidados, enfim como doentes.

A experiência de cuidar de um paciente alcoolista mobiliza não apenas o cuidador, mas toda a família. Envolve um retraimento da sociabilidade das cuidadoras. Os pacientes alcoolistas provocam apreensão, medo de agressões e mudanças constantes de humor.

O cotidiano destas mulheres é vivido sob o olhar do conformismo e da fatalidade. O estudo deixa claro Que as cuidadoras dos pacientes alcoolistas não se sentem satisfeitas por desempenhar este papel. As cuidadoras deste estudo se mostraram como organizadoras de um cotidiano instável e sofrido.

É fundamental considerar Que as mulheres Que assumiram os cuidados de um paciente alcoolista são submetidas a desgastes físicos e emocionais, Que as transformam, em um curto espaço de tempo, em doentes em potencial, considerando que o alcoolismo é uma doença lenta e gradual.

Todos os familiares Que se apresentaram como os cuidadores principais dos pacientes alcoolistas deste estudo eram mulheres 
(mães, esposas ou ex-esposas), confirmando a literatura. Segundo Silva ${ }^{(9)}$, o cuidar de um familiar dependente, se dá no espaço da família e não é difícil apreender a razão de se colocar como atribuição feminina.

Essa constatação sugere a necessidade de aprofundar a discussão de gênero para a compreensão da não naturalização desse cuidado. Para Chauí( ${ }^{(26)}$, a mulher é destinada a procriar, amamentar a cuidar do marido, passa a ter uma percepção de seu papel como 'algo natural' e não como produto da organização social.

Um outro aspecto importante neste estudo é a dificuldade de reconhecimento da doença. Segundo as entrevistadas, a doença somente foi identificada relacionada ao momento da internação. Todavia, os pacientes já vinham apresentando problemas de comportamento há bastante tempo.

Por um lado, é possível compreender esta dificuldade referindose à valorização do consumo de álcool no Brasil, o Que dificultaria uma identificação entre um beber "normal", socialmente aceito e valorizado, e o beber "dependente". Por outro lado, as dificuldades no relacionamento com os pacientes remetem às relações de gênero desiguais e hierárquicas. Estes limites culturais certamente contribuem para a dificuldade de estabelecimento de estratégias de prevenção do alcoolismo em seu estágio inicial.

A tarefa de lidar cotidianamente com um familiar Que está temporária ou definitivamente necessitando ser cuidado no âmbito familiar não pode ser isolada da discussão sobre a relação entre o cuidado oferecido pelos serviços públicos e o realizado na esfera privada. Segundo Karsch ${ }^{(10)}$, o cuidador familiar tem uma importância crucial, principalmente no Brasil, onde as ações do Estado tornamse sempre mais insuficientes no Quadro da saúde pública.

É necessário discutir a necessidade de políticas públicas Que contemplem também os cuidadores, considerando toda a sobrecarga física e emocional a Que são submetidas estas pessoas.

\section{REFERÊNCIAS}

I. Oliveira ER, Luis MAV. Distúrbios relacionados ao álcool em um setor de urgências psiQuiátricas. Ribeirão Preto, Brasil (1988-1990). Cad Saúde Pública 1996; 12(2): 17 I-9.

2. Carlini EAI, Galduroz ICF, Noto AR, Nappo SA. Levantamento domiciliar sobre o uso de drogas psicotrópicas no Brasil: estudo envolvendo as 107 maiores cidades do país. São Paulo: CEBRID/UNIFESP; 2002.

3. Almeida Filho ND, Mari II, Coutinho E, França JF, Fernandes IG, Busnelo ED. Brazilian multicentric study of psychiatric morbidity. Britsh I Psych 1997; 17 I (1): 1-6.

4. Desjarlais R, Eisenberg L, Good B, Kleinman A. World Mental Health. Problems and priorities in low - income countries. Oxford: Oxford University Press; 1995.

5. Noto AR, Moura YG, Nappo SA, Galduróz JCF, Carlini EL. Internações por transtornos mentais e de comportamento decorrentes de substâncias psicoativas: um estudo epidemiológico nacional do período de 1988 a 1999. J Bras PsiQuiatria 2002: 51 (2): 113-121.

6. Vaissman, Magda (coord.). Alcoolismo no trabalho. Rio de Janeiro: Garamond Universitária, 2004.

7. Noto, A. R. ; Fonseca, A. M. ; Silva, E. A. ; Galduróz, I. C. F. Violência domiciliar associada ao consumo de bebidas alcoólicas: um levantamento no Estado de São Paulo. I Bras Depend Químicas 2004; 5 (1): 9-17.

8. Minayo MCS, Deslandes SF. A complexidade das relações entre drogas, álcool e violência. Cad Saúde Pública 1998 14(1): 35-42

9. Silva IP. As relações de poder no cotidiano de mulheres cuidadoras. In: Karsch UMS, organizador. Envelhecimento com dependência: revelando cuidadores. São Paulo, EDUC; 1998.

10. Karsch UM, organizador. Envelhecimento com dependência: revelando cuidadores. São Paulo: EDUC; 1988.

II. Melman J. A família e doença mental: repensando a relação entre profissionais de saúde e familiares. São Paulo, Escrituras Editora; 2001.

12. Szymansky H. Viver em família como experiência de cuidado

mútuo: desafios de um mundo em mudança. Serv Social Sociedade 2002; 71:9-25.

13. Rosa LCS. Transtorno mental e o cuidado na família. São Paulo: Cortez; 2003

14. Mendes PBMT. Cuidadores: heróis anônimos do cotidiano. In: Karsch UMS, organizador. Envelhecimento com Dependência: Revelando Cuidadores. São Paulo: EDUC; 1998.

15. Karsch UMS. Dependent seniors: families and caregivers. Cad Saúde Pública 2003; 19(3): 86 I-6.

16. Heath DB. Anthropology and alcohol studies: current issues. An Rev Anthropol 1987; 16: 99-120.

17. Neves DP. Alcoolismo: acusação ou diagnóstico? Cad Saúde Pública 2004; 20(1): 7-14.

18. Oliveira RCO. O trabalho do antropólogo: olhar, ouvir, escrever. Rev Antropol 1996; 39(1): 13-37.

19. Patton MQ. Qualitative evaluation and research methods. Newbury Park: Sage; 1990.

20. Fundação Sistema Estadual de Análise de Dados. Informações dos Municípios Paulistas (SEADE) 2005. [citado em: I I abril 2005]. Disponível em: http://www.seade.gov.br/produtos/

21. Andreoli SB, Ronchetti SSB, Miranda ALP, Bezerra CRM, Magalhães CCPB, Martin D, et al . Utilization of community mental health services in the city of Santos, São Paulo, Brazil. Cad Saúde Pública 2004; 20(3): 836-44.

22. Martin D, Andreoli SB, Quirino I, Nakamura E. Noção de significado nas pes@uisas Qualitativas em saúde: a contribuição da antropologia. Rev Saúde Publica 2006; 40 (1): 178-9.

23. Lima MS. A etiologia do álcool. In: Berlote IM. Alcoolismo hoje. $3^{\text {a }}$ ed. Porto Alegre: Artes Médicas; 1997.

24. Campos EA. O alcoolismo é uma doença contagiosa? Representações sobre o contágio e a doença de ex-bebedores. Ciênc Saúde Coletiva 2005; 10: 267-78.

25. Giffin K. Violência de gênero, sexualidade e saúde. Cad Saúde Pública 1994: 10 (supl. 1): 146-55.

26. Chaui M. Convite à Filosofia. São Paulo: Editora Ática; 1994. 